\title{
Harnessing of Mini Scale Hydropower for Rural Electrification in Nepal
}

\author{
Hari Krishna Ghimire
}

Abstract. This paper provides insight on hydropower development in general and mini-scale hydropower in particular, for rural electrification in Nepal. It also analyses the opportunities and challenges in the development of mini-scale hydropower to supply reliable electricity in remote rural areas of the country as an aid to poverty reduction and economic progress.

Key words: Mini-scale hydropower, rural electrification, poverty alleviation

Nepal, a small developing country, located on the lap of mighty Himalayas is endowed with huge potential of hydropower. Out of the theoretical potential of 83,000 MW, 42,000 MW is said to be economically viable in the present context. Apart from hydropower, no other natural resources in economically exploitable quantities are available in the country that can boost economic prosperity and raise the living standards of the people. Out of the population of 28 million, around $30 \%$ still live below the poverty line and only about $7 \%$ of the rural population has access to electricity so far. Poverty is a main cause of environmental degradation and of social conflicts in rural and mountain areas of the country. Indiscriminate uses of traditional energy sources, which are mostly available free of cost in rural areas, are causing negative consequences on the natural environment. Therefore, an alternative source of energy is required to preserve precious natural forests in rural and mountainous areas.

In the past, successive governments have not properly developed hydropower overall. Politicians and planners have been engaged in futile debates whether to give priority for the development of big, small or mini-scale hydropower schemes. Poor demand-side management, the project-oriented approach and political instability have hindered the speedy electrification process. Realizing past mistakes, the Government of Nepal (GON) had promulgated the Hydropower Development Policy 1992, the Water Resources Act and Electricity Regulation 1992, and the improved Hydropower Development Policy 2001. In recent years the policy and acts have shown some positive results in this sector. The Hydropower Development Policy of 2001, especially, places emphasis on rural electrification and the involvement of the private sector in the hydropower sector by offering a one-window policy and incentive packages.

Many power-purchase agreements (PPAs) have been signed in recent years, but rural electrification is the sector where private investors do not want to spend due to the low return on investment. Hence, a subsidy policy and community participation in rural electrification is being promoted. Rural people are encouraged to participate in grid extension and construction of integrated as well as isolated type miniscale hydropower schemes for rural electrification. In this manner, hydropower as a natural endowment that is environmentally friendly and a perennial source of electricity, has been seen to enhance the sustainable development process in Nepal, as rural electrification is an important part of the development strategy. The GON, in its 1oth five-year plan, had set the ambitious target of electrifying up to 2,60o Village Development Committees (VDCs) through the extension of the integrated national grid system. The energy needs of 1,000 more VDCs were proposed to meet by decentralized energy production systems during the 10th five-year plan. Due to the rugged mountainous terrain and scattered nature of human settlements, the national grid extension to these areas is difficult and uneconomical.

\section{Mini- and micro-hydropower development}

Although the first hydropower plant of $500 \mathrm{~kW}$ was constructed in Nepal as early as 1911, to date only 550 MW of hydropower has been developed. Classification of hydropower plants took place in 1975 when the GON established the Small Hydel Development Board (SHDB) to electrify remote district headquarters through the construction of isolated type small hydropower schemes. At that time, hydropower plants from $100 \mathrm{~kW}$ to 5,000 kW were called small-hydros, and plants of less than $100 \mathrm{~kW}$ capacity were categorized as mini/micro-hydropower plants. In 1985, the Nepal Electricity Authority (NEA) was formed as per the Nepal Electricity Act of 1984, to look after all electricity-related jobs by merging the Electricity Department, the Nepal Electricity Corporation and the SHDB. Currently, there is a separate department called the Small Hydropower and Rural Electrification Department under the NEA charged with developing and operating small hydropower schemes and carrying out rural electrification ventures through the extension of the 
national grid system.

A new classification of hydropower schemes has emerged recently for practical reasons, as different institutions are involved in the development of hydropower projects. This is also due to the liberal hydropower development policy (1992 and 2001), which is mainly meant to attract private investors and encourage the rural electrification process. Now, hydropower plants of less than $100 \mathrm{~kW}$ fall under microhydros and plants between $100 \mathrm{~kW}$ to $1,000 \mathrm{~kW}$ are called mini-hydros. Other hydropower plants between $1,000 \mathrm{~kW}$ to $10 \mathrm{MW}$ fall under small-hydros and those more than $10 \mathrm{MW}$ capacity are classified as medium and big hydros.

Thousands of traditional water wheels (ghattas) are in use throughout Nepal since early days. These primitive water wheels are being developed as multi-purpose power units (MPPUs) for agro-processing and electricity generation purposes. They are popular for the electrification of scattered and isolated settlements in the hilly areas of Nepal. During the daytime they provide mechanical power for rice hulling, grinding, oil expelling and so on, and during the night they generate electricity for lighting and recreational purposes. A number of agencies and institutions are supporting the implementation process of micro-hydropower plants (MHPs). To date, around 2,200 MHPs, including 800 mechanical schemes, have been installed, and the total installed capacity of electricity generation from these plants has reached to around 7.5 MW.

After 1970, the GON provided subsidies of up to $75 \%$ for electro-mechanical equipment for microhydropower plants through the Agricultural Development Bank, Nepal (ADB/N)) to electrify remote rural areas of the country. But, from 1995/96 onward the process for implementation of micro-hydropower schemes took new momentum as a new institution called the Alternate Energy Promotion Centre (AEPC) was established under the Ministry of Science and Technology. The main objective of AEPC is to promote and disseminate renewable/alternative energy technologies and meet basic energy needs of rural people residing in remote areas of the country. AEPC administers provide subsidies to enthusiastic microhydropower developers through its interim rural energy fund supported by the Energy Sector Assistance Program (ESAP). Apart from AEPC, there are other institutions and organizations like the UNDP's Rural Energy Development Program (REDP), the government's Remote Area Development Committee (RADC) and the Annapurna Conservation Area Project (ACAP).

\section{Challenges and opportunities}

Around $30 \%$ of the total population of Nepal live below the poverty line, and most reside in remote rural areas. Many people who live in rural and mountain areas are mired in poverty and destitution. They do not have access to modern development and new technologies. Productivity in these areas is very low because of primitive and traditional farming methods. Sufficient arable lands with irrigation facilities are not available in most rural hilly communities. Agricultural products from limited land areas are inadequate to feed the local people. Natural forest areas are being destroyed for new farming lands. Fuelwood, agricultural residues and animal wastes are widely used to fulfill basic energy needs. Even now, in some farflung rural areas of Nepal, pine sticks are used for lighting. Kerosene is a luxurious item, costing the equivalent of around US\$ 1 to 2 per liter. Deforestation is rampant, causing multi-dimensional consequences to the environ-ment.

To alleviate the misery of the rural people and to raise their minimum living standards, a supply of adequate and reliable electricity is essential. Where extension of the national grid line is not possible in the near future, and where the establishment of diesel power plants is too expensive, a dependable supply of hydro energy is only the long-term solution. As there are 6,000 rivers and rivulets criss-crossing the country, plenty of potential mini-scale hydropower sites can be found in the rural mountain areas. The promotion of tourism, the establishment of small industries and the provision of lift irrigation are some features that will certainly stimulate the local economy. Hilly mountain regions are favorable for growing varieties of fruits and valuable herbal species; but due to the lack of appropriate markets and processing and transportation facilities, rural farmers are not greatly interested in growing such products.

Experience shows that a qualified and trained manpower is needed to run sophisticated electricity generating equipment. In the case of mini/micro-hydros, it is not economical to send an expert for maintenance to remote area for a low $\mathrm{kW}$ capacity generating plant. All responsibilities of consultants and contractors are completed once the commissioning of energy generating plant is over. But, future problems remain with the poor promoter with limited technical and financial ability. The life of a hydropower plant could be $70-80$ years or more, if it is properly maintained and operated. Some micro- and minihydropower plants built in the past could not be connected to the national grid due to technical as well as economic reasons. Usually, owing to better quality and reliability, people prefer to have grid electricity than 
electric energy supplied from a stand alone plant.

Given this background, it is obvious that there should be a multi-pronged strategy of rural electrification in Nepal. Both the implementation of mini-micro-hydropower plants and extension of the national grid system should go ahead together, based on principles of comparative advantage and economic efficiency. The NEA, as a public utility, has a responsibility of planning, implementation and management all major electricity supply installations in the country. The NEA has hinted positively and has agreed to work together with AEPC and SHPP (the Small Hydropower Promotion Project) for the grid connection of microhydropower plants wherever technologically and economically viable. Recently, the concerned parties have agreed in principle to implement two pilot schemes for grid connection-one in the range of 15 to $25 \mathrm{~kW}$ and another from 50 to $100 \mathrm{~kW}$.

Although, theoretically, grid connection of a hydropower generating plant (even if it is of one $\mathrm{kW}$ ) is possible, without technical and economic analysis there is no point promoting it (obviously with limited subsidy in the case of micro-hydros). One recent experimental study carried out by the Electrical Department of the Institute of Engineering of Tribhuvan University shows that hydropower plants of less than 10 kilowatts cannot be considered for grid connection in the current context.

\section{Conclusion}

Hydropower as a non-polluting, environmentally friendly, renewable, locally available and reliable source of energy that needs to be exploited to the fullest extent possible, to meet national energy objectives in the Nepal context. Due to the unique operating characteristics of hydropower plants, reliability and stability of power grid can be achieved. For economic and social development, a dependable supply of electricity is a necessity. In a country where (apart from hydropower) other energy resources of an economically exploitable scale are not available, hydropower development is an important means to provide reliable and affordable electricity.

Electrification may not be a big problem where the national grid can be extended economically. In very remote areas, however, where the national grid cannot be extended in the near future due to economic reasons, a group of interconnected mini-hydropower plants seems to be a viable proposition for the total electrification of the country. For this purpose, project sites, target areas and load centers should be carefully selected and implemented. Over the long run, local grids can be connected to the national grid system and the system can function economically and reliably. With its limited technical ability and financial resources, Nepal alone is not in a good position to construct mini-scale hydropower plants and establish local grids in all remote hilly areas of Nepal. Hence, the government of Nepal should create a conducive environment for foreign assistance and should request developed countries of the world to offset investment under carbon swaps and clean development mechanisms.

Nepal has more than 90 years of experience in the field of mini-scale hydropower development. Many success and failure stories have happened during this period. Many governmental, non-governmental and private agencies are involved in the field of mini/micro-hydropower development, including almost twodozen manufacturers/installers and an equal number of specialized consulting agencies. Acquired experiences and technological as well as managerial achievements in this sector can be one of the agendas for mutual cooperation among the SAARC countries. Nepal also can benefit from friendly countries of the SAARC region that have experience in the field of larger hydropower schemes.

Hari Krishna Ghimire is Deputy Manager, Nepal Electricity Authority

Corresponding address: hkghimire@mail.com.np 